Chapter 17

\title{
Synthesis and Characterization of Ti-Si-C-N Nanocomposite Coatings Prepared by a Filtered Vacuum Arc with Organosilane Precursors
}

\author{
Seunghun Lee, P. Vijai Bharathy, T. Elangovan, \\ Do-Geun Kim and Jong-Kuk Kim \\ Additional information is available at the end of the chapter \\ http://dx.doi.org/10.5772/51059
}

\section{Introduction}

Many deposition tools such as magnetron sputtering, plasma enhanced chemical vapor deposition (PECVD), arc ion plating (AIP), and filtered vacuum arc (FVA) have been introduced for synthesizing nanocomposite films. Table 1 summarizes previous works of nanocomposite coatings. Nanocomposites based on TiN have been investigated dominantly with the incorporation of silicon or carbon contents. The incorporation methods such as an alloy arc cathode, addition of reactive gas, and additional magnetron sputtering have been used to deposit ternary or quaternary composition nanocomposite films. The magnetron sputtering and PECVD have been firstly used to grow nanocomposite films due to the simplicity of controlling a composition ratio becuase precise control of additional components is important to make a nanocomposite structure. For example, Ti-Si-N nanocomposite films have showed the maximum hardness at Si content of $9 \pm 1$ at.\% [1]. After that, a vacuum arc discharge has been applied to the nanocomposite coatings becuase the vacuum arc process has many advantages against other CVD or PVD processes. A vacuum arc plasma exhibits high ionization ratio more than $90 \%$. Also the ion energy in a vacuum arc is in the range of $10-100$ $\mathrm{eV}$. Hence, the effect of ion energy on the film structure appears significantly [2]. Nevertheless, the vacuum arc method cannot avoid the problem of macro particles. Macro particles generated from arc spots are the main drawback of the vacuum arc process. The macro particles form micro cracks or pin holes, resulting in a bad corrosion resistance when coatings are exposed in some corrosive environments. 
In FVA, magnetic filters have been introduced to transport plasma except the macro particles. The filters transport charged particles selectively using electromagnetic fields. However, neutral macro particles collide with a wall by an inertia drift. Main issues are the efficient removal of the macro particles and the minimization of ion loss through a magnetic filter wall. The effective way to reduce the macro particles is based on the spatial separation of the trajectories of macro particles and ions [3]. If the magnetic field is curved such as the field inside a curved solenoid, electrons follow the curvature. The electrons are said to be magnetized. In contrast, ions are usually not magnetized because the gyration radius of ion is much larger than that of electron. Nevertheless the ions are forced to follow the magnetic field lines due to the electric fields between electrons and ions. Therefore ions and electrons are transported along magnetic field lines [4]. Various FVA methods have been widely applied to the nanocomposite deposition without any macro particle problems. Magnetic filtering technology removes efficiently the macro particles and result in a smooth film surface $[5,6]$.

\begin{tabular}{llll}
\hline Method & Material & Hardness & Ref. \\
\hline Arc & Ti-Si-N & $45 \mathrm{GPa}$ & {$[1]$} \\
\hline Arc & Ti-Al-N/Cr-N & $37 \mathrm{GPa}$ & {$[7]$} \\
\hline Arc & Ti-Al-Si-N & $34 \mathrm{GPa}, 42.4 \mathrm{GPa}$ & {$[8,9]$} \\
\hline Arc & Ti-Al-N & $35.5 \mathrm{GPa}$ & {$[10]$} \\
\hline Arc, magnetron sputter & TiN-Cu, CrN-Cu, MoN-Cu & $27-42 \mathrm{GPa}$ & {$[11]$} \\
\hline Arc, magnetron sputter & Ti-Si-N & $45-55 \mathrm{GPa}$ & {$[12,13]$} \\
\hline FVA, magnetron sputter & Ti-Si-N & $45 \mathrm{GPa}$ & {$[14]$} \\
\hline FVA, magnetron sputter, E-beam & Ti-Cr-N,Ti-B-C & $43.2 \mathrm{GPa}$ & {$[15,16]$} \\
evaporation & & & {$[17]$} \\
\hline FVA & Ti-Si-N & $40.1 \mathrm{GPa}$ & {$[18,19]$} \\
\hline PECVD & Ti-Si-N & $3500 \mathrm{HK}\left(\mathrm{kg} / \mathrm{mm}^{2}\right), 40 \mathrm{GPa}$ & {$[20]$} \\
\hline PECVD & Ti-Si-C-N & $48 \mathrm{GPa}$ & {$[21]$} \\
\hline PECVD & Ti-Si-C-N & $52 \mathrm{GPa}$ & {$[22,23]$} \\
\hline Magnetron sputter & Ti-Si-N & & \\
\hline
\end{tabular}

Table 1. Nanocomposite coatings by various methods.

Several studies found the maximum efficiency and the optimum condition for the curved magnetic filters. An analysis of plasma motion along the toroidal magnetic field has been shown that plasma that is transported by the magnetic field in a guiding duct should satisfy the following relation [24],

$$
\mathrm{B}>\mathrm{M}_{\mathrm{i}} \mathrm{V}_{3} / \text { Zea }
$$


where $M_{i}$ is the ion mass, $V_{o}$ is the translational velocity, $Z$ is the charge multiplicity of the ion, $e$ is the electron charge, and $a$ is the minor radius of the plasma guiding duct. The transport of heavy metal ions having an energy of even a few tens of eV requires strong magnetic field above 1 Tesla to fulfill the inequality in Eq. (1). However, it is practically impossible to provide a stable burning of the direct current arc discharge in the strong magnetic field. Therefore, it is reasonable to consider heavy-element plasma flow transport in a curvilinear system with crossed electric and magnetic fields using the principles of plasma optics as a guide $[25,26]$. In this case, the required magnetic field is determined by the following condition, $\rho_{e}<a<\rho_{i}$, where $\rho_{e}$ and $\rho_{i}$ are the electron and ion Larmor radius, respectively. The required field is significantly lower than the fields defined by the expression in Eq. (1). Electron Larmor radius is

$$
\mathrm{r}_{\mathrm{e}}=\left(\mathrm{m}_{\mathrm{e}} \mathrm{kT} \mathrm{T}_{\mathrm{e}}\right)^{1 / 2} / \mathrm{eB}
$$

where $m_{e}$ is the electron mass, $k$ is Boltzmann constant, and $T_{e}$ is the electron temperature.

Note that electrons are only magnetized, while the ions are not. The electrons move along the magnetic field lines. Due to the highly conductive plasma, the magnetic field lines are equi-potentials. Considering a plasma diffusion in vacuum, electrons have higher mobility than ions due to smaller mass except at a sheath boundary. However, electrons expand with the same velocity as ions because electrostatic forces keep the electrons and ions together. And a cross field diffusion is given by the Bohm formula, $D_{B}=k T_{e} / 16 B$, though the cross field diffusion coefficient, $D$, is proportional to $B^{-2}$ in the classical theory[27].

Anders mentioned about the criterion of system efficient, $K_{s}$, which is generally considered as the ratio of the total ion flow at the exit of the system, $I_{i}$, to the arc discharge current, $I_{a}$ as follows,

$$
\mathrm{K}_{\mathrm{s}}=\mathrm{I}_{\mathrm{i}} / \mathrm{I}_{\mathrm{a}}
$$

The system coefficient is typically $1 \%$ [6]. There is a general agreement that the transport efficiency is maximized by focusing the plasma into the duct and biasing the duct to a positive potential of $20 \mathrm{~V}$. Predictions of the available maximum transmission vary between 11 and $25 \%$ depending on the ion energy [28]. In practice, the transport of plasma produced by pulsed high current arcs (HCA) was showed that the system coefficient was $7 \%$ [6]. For linear FVA, the maximum value of the system efficiency reached $8 \%$ when arc current Ia was adjusted in the range of 100-110 A and the magnetic filter field was $20 \mathrm{mT}$ [29].

To supplement the accuracy of system coefficient, a particle system coefficient, $K_{p}$, is proposed to eliminate the influence of the various ion charge states by considering the mean ion charge state, $Z_{a v}$ of the used metal as follows.

$$
\mathrm{K}_{\mathrm{p}}=\mathrm{I}_{\mathrm{i}} / \mathrm{Z}_{\mathrm{av}} \mathrm{I}_{\mathrm{a}}
$$


Because the average ion charge state is taken into account, the particle system coefficient is more closely related to the deposition rate [30]. However this can be particularly insufficient for filter optimization when the system used a graphite cathode that generates solid rebounding macro particles.

The problem has been solved by the numerical calculation of the particle trajectories using a two-dimensional approximation [31]. In the calculation, it assumes that the macro particles are solid spheres, the inner surfaces of the plasma guide, and the intercepting fins are smooth, the repulsion of particles from a guiding duct wall is partially elastic, the particles are emitted froma cathode spot with equi-probability in any direction. The computing results make it possible to estimate the ratio of the pass of macro particle flow, $N_{e x}$, to the flow, $N_{\text {ent }}$ generated by the cathode spot. The ratio $N_{e x} / N_{\text {ent }}$ characterizes the likelihood of an macro particle passing through the system. The results of simulations indicate that the absence of a direct line-of-sight between the cathode and the substrate is not always sufficient to provide the required degree of macro particle removal from the plasma. The results of computations performed for various magnetic filters are presented in Table 2 [27].

\begin{tabular}{ccccccccc}
\hline Filter type & Knee $\mathbf{( 4 5}^{\circ}$ ) & Torus $\mathbf{( 4 5}^{\circ}$ ) & Rectang. & Dome & Torus (90 & Retil. & Radial & Wide apert. \\
\hline $\begin{array}{c}\mathrm{N}_{\text {ex }} / \mathrm{N}_{\text {ent }}[\%] \\
\text { (predicted) }\end{array}$ & 1.7 & 25.0 & 17.0 & 1.7 & 0 & 4.4 & 0 & 0 \\
\hline $\begin{array}{c}\text { Transport [\%] } \\
\text { (measured) }\end{array}$ & 3.0 & 2.5 & 2.5 & 2.5 & 1.5 & 1.8 & 8.4 & $\sim 6.0$ \\
\hline
\end{tabular}

Table 2. Fitlering $\left(N_{\text {ex }} / N_{\text {ent }}\right)$ and transporting properties of magnetic plasma filters [27].

There are various types of filters as shown in Fig. 1[32]. Most types are used magnetic fields to transport plasma without macro particles. Several types only use the collisional reduction of macro particles. In most cases a plasma is transported from the cathode to the substrate, and the droplets are eliminated by a plasma transportation wall, guiding duct. Many review papers of the filtered arc system and technology have been reported [6,33-38]. A typical filtered arc system with its different electromagnetic plasma transportation duct or droplet filter configurations is shown in Fig. 1(a)-(h). Electromagnetic coils transporting plasma in the out of line of sight direction can be positioned in the chamber, instead of placing them outside of the filter duct. The off-plane double bend filter is nicknamed FCVA and is now commercially available $[39,40]$. Most FAD units have electromagnetic coils outside of the plasma duct and have baffles inside the duct wall. However, some types have freestanding coils inside the plasma duct or the chamber. Other interesting filters have been developed. Examples are shown in Fig. 1(i)-(l). In the Venetian-blind filter, the plasma passes between the vane lamellae, and the droplets are caught or reflected by the lamellae [41,42]. A coaxial filter is operated with a large current pulse, and the plasma is driven by a self magnetic field [43]. An electrostatic filter can be used with a pulsed arc having a laser trigger [44]. However, recently only the laser triggered arc is used without the electrostatic filter. Mechanical filters can be used in a pulse arc [45], which may also be used in pulsed laser deposition [46]. 


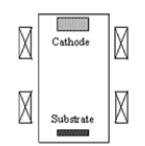

(a)

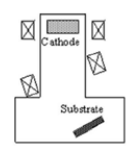

(b)

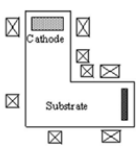

(c)

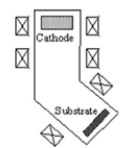

(d)

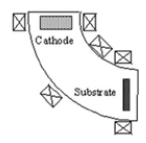

(e)

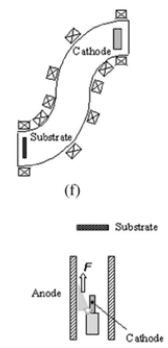

(j)

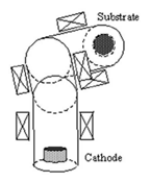

(g)

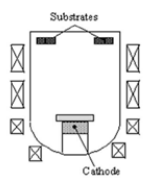

(h)

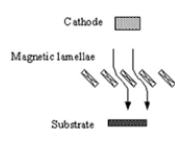

(i)

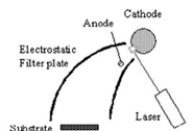

(k)

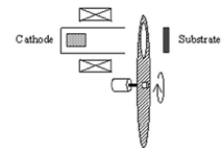

Figure 1. Various types of filter systems [32]. (a) Rectilinear. (b) Bent. (c) Rectangular. (d) Knee. (e) Torus. (f) S-shape. (g) Off-plane double bend. (h) Dome. (i) Venetian blind. (j) Co-axial (pulse). (k) Electrostatic filter with laser trigger (pulse). (I) Mechanical pulse.

\section{Nanocomposite Films Prepared by a FVA With an Organosilane Precursor}

\subsection{Basic Configuration of Deposition System for an Organosilane Incorporated FVA}

Ti-Si-C-N quaternary nanocomposite coatings were prepared by using a filtered vacuum arc deposition system. Figure 2 represents the schematic diagram of the FVA coating system. The deposition system consists of a water-cooled cathode and anode, plasma guiding duct, and magnet coils. The diameter and height of the chamber is 800 and $650 \mathrm{~mm}$, respectively. The vacuum arc discharge from cathode emits high energy $(\sim 60 \mathrm{eV})$ ions and generates dense plasma above $10^{13} \mathrm{~cm}^{-3}$. An arc spot also makes neutral macro particles, which cause several problems such as rough surface, pinhole, and micro cracks in coatings. To remove the macro particles the plasma guiding duct and magnet coil were used. Coaxial magnetic fields about $15 \mathrm{mT}$ were generated by six magnetic coils. The pumping system consists of rotary pump (900 l/min) and oil diffusion pump (1500 l/s). The ultimate pressure of deposition chamber was $2 \times 10^{-6} \mathrm{mTorr}$ by using rotary and diffusion pumps. MKS mass flow controllers were used to regulate the flow rate of tetramethylsilane (TMS) (99.99\%), argon (99.999\%) and nitrogen (99.99\%) gases. 
The samples are mounted on the rotational substrate holder with a rotational speed of $3 \mathrm{rpm}$ for the deposition of the coatings. The deposition process consisted of Ar ion bombardment cleaning, $\operatorname{Ti}(100 \mathrm{~nm}) / \mathrm{TiN}(200 \mathrm{~nm})$ interlayer deposition to improve an adhesion strength. The thickness of the Ti-Si-C-N nanocomposite coating was about 0.4 to $0.6 \mu \mathrm{m}$. The experimetal details are shown in Table 3.

Structural characterization of as-obtained samples was done by X-ray diffraction (Shimadzu XRD-6000, Cu K $\alpha$ radiation $\lambda=1.5406 \AA$, scanning rate $1^{\circ}$ min-1) and transmission electron microscopy (JEOL JEM-3100 FEF-UHR, $300 \mathrm{kV}$ ). The crystallite size was determined by Scherrer formula and lattice parameter of coating was calculated by Bragg law for the cubic system.

Elemental analysis and chemical nature of coatings were performed with X-ray photoelectron spectroscopy (XPS), using a VG Scientific ESCALAB 250 spectrometer with a Mg K $\alpha$ Xray source. Hardness are assessed by means of a nanoindentation system (MTS, nano indenter $\mathrm{XP}$ ) using a Berkovich diamond indenter. Coating hardness was determined from the loading and unloading curves employing depth-sensing hardness testers. The applied load was gradually increased to $3000 \mu \mathrm{N}$ at a loading rate of $150 \mu \mathrm{N} / \mathrm{s}$, and was held at this maximum value for $10 \mathrm{~s}$. Testing was done using the constant-displacement-rate mode until a depth of $200 \mathrm{~nm}$ was reached and the values from fifteen indents were averaged for each condition. Adhesion strength was measured by a scratch tester (J\&L, Scratch Tester). The applied load on the diamond tip (tip radius $200 \mu \mathrm{m}$, conical angle $120^{\circ}$ ) was continuously increased at a rate of $0.25 \mathrm{~N} / \mathrm{s}$, while the tip advanced at a constant speed of $0.05 \mathrm{~mm} / \mathrm{s}$.

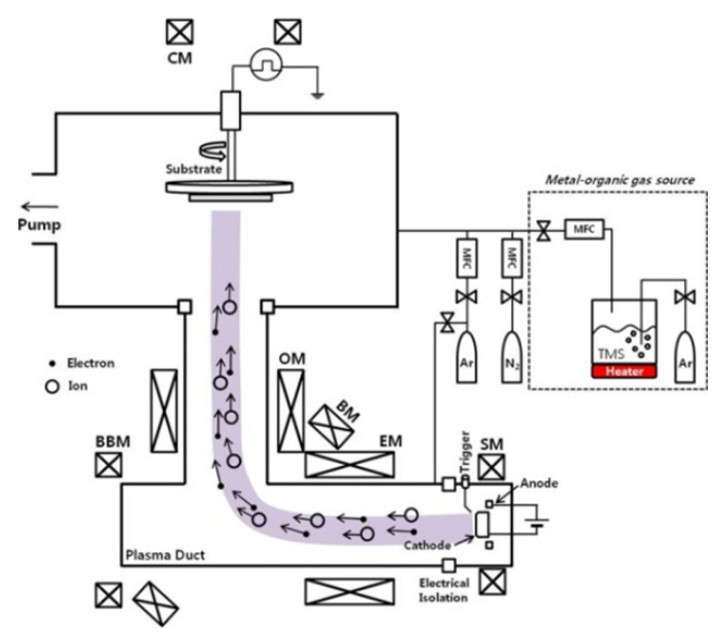

Figure 2. Experimental schematics of filtered vacuum arc with organosilane vaporizations. 


\begin{tabular}{cc}
\hline Arc voltage & $24 \mathrm{~V}$ \\
\hline Arc current & $60 \mathrm{~A}$ \\
\hline Duct voltage & $25 \mathrm{~V}$ \\
\hline Duct current & $43 \mathrm{~A}$ \\
\hline Substrate voltage & $0 \sim-400 \mathrm{~V}$ \\
\hline Base pressure & $2.3 \times 10^{-6} \mathrm{Torr}$ \\
\hline Total pressure & $8.2 \times 10^{-4} \mathrm{Torr}$ \\
\hline Deposition rate & $9-38 \mathrm{~nm} / \mathrm{min}$ \\
\hline N2 flow rate & $50 \mathrm{sccm}$ \\
\hline TMS flow rate & $10 \mathrm{sccm}$ \\
\hline Substrate Temperature & $<150^{\circ} \mathrm{C}$ \\
\hline
\end{tabular}

Table 3. Experiment details.

\subsection{Ti-Si-C-N Nanocomposite Film Prepared by a FVA With TMS Gas}

\subsubsection{Composition and Chemical Analysis}

XPS analysis is used to identify a chemical composition on the surface of the nanocomposite coating. Surface pre-sputtering eliminated the surface oxide at air-exposed samples. The elemental compositions for $\mathrm{Ti}, \mathrm{Si}, \mathrm{C}$ and $\mathrm{N}$ as a function of TMS flow rate from 5 to $20 \mathrm{sccm}$ are given in Fig. 3. A strong increase of the $\mathrm{Si}(2.1 \pm 1$ to $12.2 \pm 1$ at. \%) content is observed up to the TMS flow rate of $20 \mathrm{sccm}$. Ti and $\mathrm{N}$ content showed decreasing trend from $18.8 \pm 1$ to $9.83 \pm 1$ at. $\%$ and $24.8 \pm 2$ to $19.14 \pm 2$ at. $\%$, respectively. Whereas the carbon content remained constant in the range of $31 \pm 2$ at. \%.

The XPS spectra of of Ti 2p, Si 2p, and N 1s are shown in Fig. 4 . Fig. 4 (a) depicts the XPS spectrum of Ti $2 p$. The characteristic doublet of Ti $2 \mathrm{p}_{3 / 2}$ and $2 \mathrm{p}_{1 / 2}$ are clearly observed. The Ti $2 \mathrm{p}_{3 / 2}$ peak position shows positive shift from $460.85 \mathrm{eV}$, which reveals a good agreement value of $460.5 \mathrm{eV}$ for TiN. This peak position shifts to higher value at silicon content of 3 at. \% and then it moves to lower binding energy (BE) side at silicon content at 8 at. \%. The second peak position $\mathrm{Ti} 2 \mathrm{p}_{1 / 2}$ is showing at $455.15 \mathrm{eV}$ matching with Ti- nature bonding position of TiN. It is well known that $\mathrm{TiN}_{x}$ has flexible chemical states governed by the compactness of other small non-metal atoms filled in the octahedral voids of titanium [47]. Fig 4 (b) shows the high resolution spectrum of $\mathrm{N} 1 \mathrm{~s}$ region. The three peaks correspond to 398.5, 396.8 and $400.6 \mathrm{eV}$, are in agreeing with the binding energies of $\mathrm{Si}_{3} \mathrm{~N}_{4}, \mathrm{TiN}$ and $\mathrm{TiC}$, respectively. With increasing silicon content the N1s peak position showeda negative shift from 396.8 to 396.6 eV. Fig 4 (c) shows Si 2p spectra peaks, which are observed at 101.8, 101.1 and $102.8 \mathrm{eV}$, are attributed to the $\mathrm{Si}_{3} \mathrm{~N}_{4}$, the $\mathrm{Si}(2 \mathrm{p})-\mathrm{C}$, and $\mathrm{Si}(2 \mathrm{p})-\mathrm{O}$ bonds, respectively. The incorporation of TMS at low Si content (2 at.\%) results in $\mathrm{Si}_{3} \mathrm{~N}_{4}$ formation, whereas $\mathrm{SiC}$ formation is dominant at the high Si content (12 at.\%). The reason is that $\mathrm{CH}_{3}$ in TMS is not dissociated perfectly in arc plasma so the carbon content are incorporated and react with Si contents. From the XPS results, it was concluded that $\mathrm{Si}$ in $\mathrm{Ti}-\mathrm{Si}-\mathrm{C}-\mathrm{N}$ coatings existed mainly as amorphous silicon nitride with some silicon carbide. 


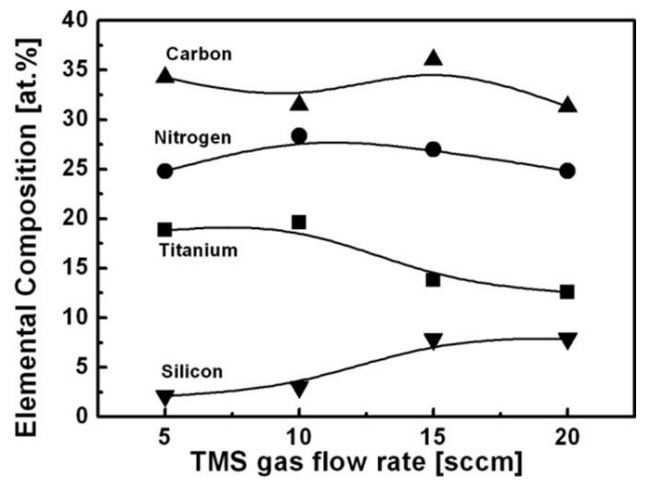

Figure 3. Chemical composition of Ti-Si-C-N nanocomposite films as a function of TMS flow rate.

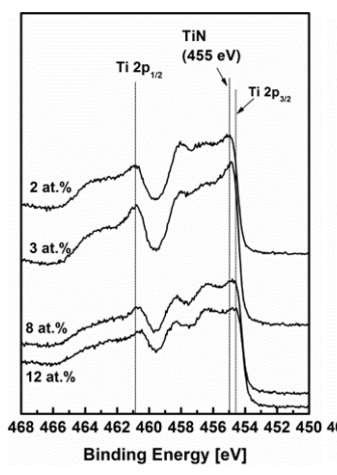

(a)

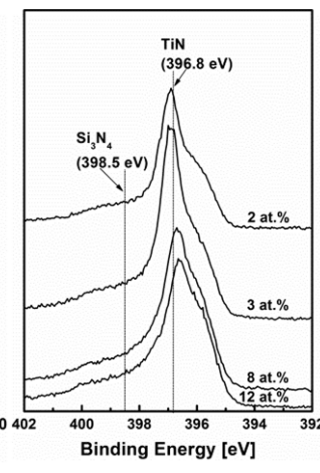

(b)

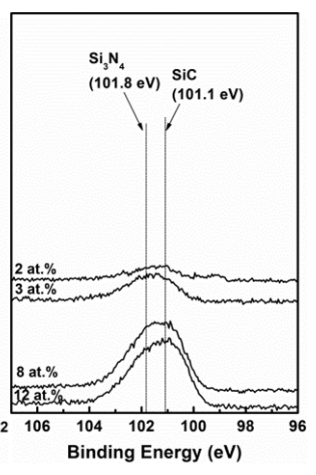

(c)

Figure 4. XPS spectra of Ti-Si-C-N nanocomposite films. (a) Ti (2p), (b) Si (2p), (c) N (1s).

\subsubsection{Microstructure Analysis}

X-ray diffraction (XRD) is used to investigate the crystalline phases of the Ti-Si-C-N coating. Figure 5 shows the XRD pattern of Ti-Si-C-N coating with different silicon contents. The TiSi-C-N nanocomposite coatings with silicon content range of 2.1 to 16.2 at. \%, exhibit the diffraction peaks at the angles of $2 \theta=36.01^{\circ}, 43.63^{\circ}$ and $50.79^{\circ}$ which are corresponding to (111), (200) and 220) TiCN reflections respectively [14,48-52]. These positions of the three peaks are coinciding with the values obtained in the JCPDS card [53]. Also, peak is observed at $38^{\circ}$ that are attributed to the diffraction of stainless steel, which is the substrate. No signals from the phase formation of $\mathrm{Si}_{3} \mathrm{~N}_{4}$ or from titanium silicide can be observed [54,55]. Note that the amorphous phase $\mathrm{Si}_{3} \mathrm{~N}_{4}$, deduced from the XPS results analysis, has been confirmed with the XRD measurement. 
The crystalline size of the Ti-Si-C-N coating is calculated from the TiN (111) diffraction peak. The TiN (111) peak is fitted by using a Gaussian function to calculate the crystallite size from FWHM by using Scherrer equation. Adding Si, the crystallite sizes decreases from 3 to $2 \mathrm{~nm}$, which shows that nanocrystalline phases are formed. It representsthat the addition of silicon could reduce the grain coarsening in the Ti-S-C-N nanocomposite coatings.

Figure 6 shows HRTEM picture acquired on the Ti-Si-C-N coating contain 3 at. \% of Si. The lattice spacing of these crystallites is $0.212 \mathrm{~nm}$. The amorphous phase has an irregular shape and a boundary surrounding the TiN nanocrystallites. The growth direction of (111) plane is clearly identified in this image. The image shows the fine grain structure and reveals that these fine grains are largely oriented in the direction of growth. An arrow indicated the growth direction. TiN nanocrystals with an average grain size of about $10 \mathrm{~nm}$ were separated by less than $1 \mathrm{~nm}$ thick brighter $\mathrm{Si}_{3} \mathrm{~N}_{4}$ tissues. Fig. 6 (b) shows a STEM image of Ti-Si-C-N coating and the intensities from $\mathrm{Ti}, \mathrm{Si}, \mathrm{C}$, and $\mathrm{N}$ obtained from an EDX line scan acquired from the STEM image. In the matrix, the Ti and the Ti signals are high and small for silicon small signals are observed from the XRD, XPS and TEM analysis results, it could be confirmed that the Ti-Si-C-N coating obtained in this experiment consisted of nanosized TiN crystallites surrounded by thin amorphous phase of $\mathrm{Si}_{3} \mathrm{~N}_{4}[56]$.

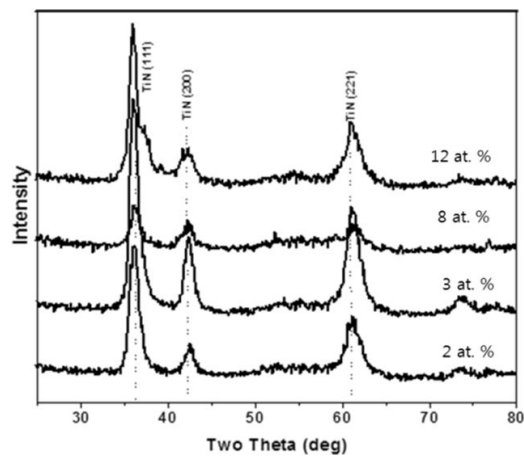

Figure 5. X-ray diffraction patterns at various Si contents from 2 to 12 at. \%.

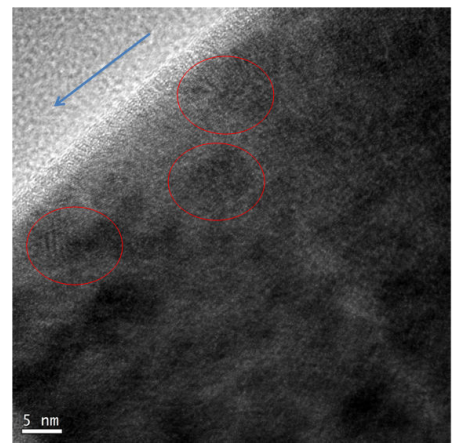

Figure 6. HRTEM image of Ti-Si-C-N at 3 at.\% of Si content. 


\subsubsection{Mechanical Properties}

The nano-indentation technique permits to extract the surface mechanical properties from depths of nanometers. Hardness can be calculated using Oliver and Pharr method [57]. The hardness decreases with increasing the depth of indentation at extremely small depths. This indentation sizes effect is expected for soft metal films and has been related to strain gradient plasticity. In the present study, nano-hardness of the Ti-Si-C-N coatings was obtained as a function of depth up to a maximum depth of $180 \mathrm{~nm}$. The steel substrate hardness is around 2 GPa and Young's modulus is $200 \mathrm{GPa}$ as obtained by nano-indentation experiments. Load versus indentation depth curves from multiple experiments by using the same maximum load and from 25 different sample locations were averaged and standard deviations were calculated and reported. Figure 7 represents the hardness of Ti-Si-C-N coatings as a function of displacement into surface. The hardness values of Ti-Si-C-N coatings are 18, 35,32 and $27 \mathrm{GPa}$ at a contact depth of $40 \mathrm{~nm}$ at 2.1, 3, 7 and 8 at. \% of Si, respectively. The maximum hardness of $\sim 35 \mathrm{GPa}$ is obtained for the silicon content of 3 at. \%. The hardness value of $48 \mathrm{GPa}$ was achieved adding 10 at.\% Si and 30 at.\% C by Dayan Ma et.al [58]. Also he was explained it with carbon contents. Suddeep mabiraham et. al [49] also achieved the hardness of the Ti-Si-C-N films at the Si content of 9.2. at \% with maxiumum hardness around $55 \mathrm{GPa}$ achieved with Si content of 8.9 at.\%. by using PVD method in [59]. So far many people have been reported the hardness of the Ti-Si-C-N coating at above 5 at. \% of the silicon content. Present results show that the maximum increases in hardness for Ti-Si-C$\mathrm{N}$ coating within 3 at. \% of silicon, which proves such hardening effects, is known to occur in transition metal nitride systems with a few at. \% of silicon content and this increased hardness effect due to hindrance effect of the segregated $\mathrm{Si}_{3} \mathrm{~N}_{4}$ on TiN grain boundary sliding which is the predominant deformation mechanism in nanocrystalline materials [60]. On the other hand, the hardness reduction with a further increase in Si content is observed [58]. The decrease in hardness is due to increasing contributions from the soft substrate.

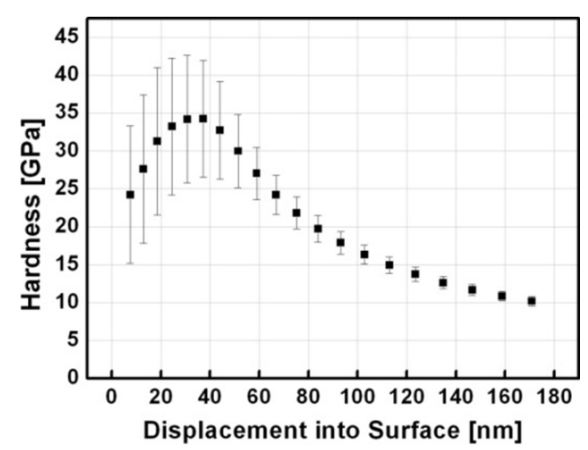

Figure 7. Nano indentation of Ti-Si-C-N films with 3 at. \% of Si. 


\subsubsection{Adhesion Properties}

Scratch tests with ramping loads up to $100 \mathrm{~N}$ were conducted on the films deposited on stainless steel substrates. The critical load required to cause the first delamination at the edge of the scratch track (adhesive failure) characterizes the adhesion properties of coatings. Optical microscopy of the films subjected to the scratch tests (Not shown here). The critical loads obtained for the above four coatings were 37, 44, 33 and $30 \mathrm{~N}$, respectively. Strong acoustic signals were observed for the critical load exceeding $30 \mathrm{~N}$. The lowest value of COF of 0.16 is obtained for the hardest film with Si content of 2.1 at.\% and it is $0.17-0.22$ for the rest of nanocomposite films and agrees with the literature [59, 61]. For FVA deposition, the intrinsic energy of ions emitted from a cathode source is considerably higher as compared to the evaporated or sputtered atoms. This higher ion energy up to $60 \mathrm{eV}$ condenses deposited film and enhances adhesion. Beside that the friction coefficient and penetration depth versus force show several inflections for the Ti-Si-C-N with 8 at. \% Si.

\subsection{Substrate Bias Effects on Ti-Si-C-N Nanocomposite Films}

\subsubsection{Structural Properties}

The deposition rate of Ti-Si-C-N nanocomposite coating was found to decrease gradually from 18 to $8 \mathrm{~nm} / \mathrm{min}$, when the bias voltage increased from 0 to $-400 \mathrm{~V}$. The decreasing trend of deposition rate has been explained on the basis of removal of impurities and densification of films due to the energetic ion bombardment when increased substrate bias voltage [62].The XRD diffraction of Ti-Si-C-N nanocomposite coating for different substrate bias voltage is as shown in Fig. 8. It matches well with the ICDD PDF 42-1489 revealing the $\mathrm{NaCl}$ type crystal structure. However, the diffraction peaks are shifted towards the higher angle side indicating the presence of compressive stress in the coatings [63]. At zero bias voltage, coating shows predominant presence of (111) and (200) orientations. With increase in substrate bias, (220) was found to dominate the spectra especially at substrate biases of $-300 \mathrm{~V}$ and $-400 \mathrm{~V}$. This behavior has been observed in binary, ternary and quaternary coatings and is attributed to the decrease in sputtering rate at higher substrate bias. There is no further detail of the Ti-Si-C-N coating with effect of bias voltage by using FVA system. These result show that substrate bias voltage has a strong influence on the structural properties of the deposited films and will be correlated with changes in hardness of the coatings. Fig. 9 shows the calculated lattice parameters from the XRD pattern for TiN peak position using equation (1). The lattice constant of TiN changes from 4.31599 to 4.24762 Á with the different substrate bias voltages. For $-100 \mathrm{~V}$ bias voltage, TiN films are over stoichiometric corresponding to the highest lattice parameter (ICDD PDF 42-1489) a =4.29 Á). The shift could be attributed to higher residual stress in the coatings and changes in the composition of the coating. The calculated lattice parameter was shown $4.24762 \AA$ at $-400 \mathrm{~V}$, it is slightly lower than that of the value reported standard lattice parameter. Usually these kinds of stress with increasing bias voltage are commonly observed in thin films grown by physical vapour deposition methods. With increasing bias voltage, the ion bombardment encouraged mobility of atoms was major effect which implies that the decreasing trend of the stress because of enhanced annihilation of defects [64]. 


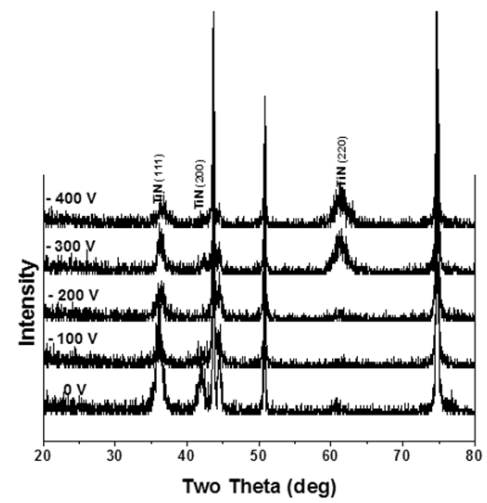

Figure 8. X-ray diffraction patterns of Ti-Si-C-N nanocomposite coatings various substrate bias voltage.

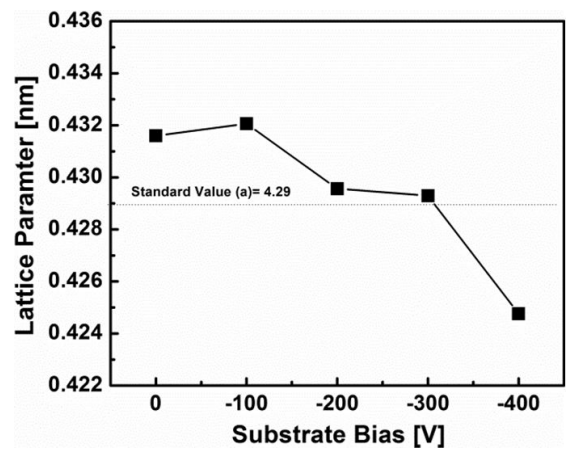

Figure 9. Lattice parameter of the Ti-Si-C-N nanocomposite coatings various substrate bias voltage.

\subsubsection{Texture Orientation}

The changes in the preferred orientation of Ti-Si-C-N nanocomposite coating as a function of the substrate bias are qualitatively estimated in terms of texture coefficients (TC). The TCs, determined by TC $=\mathrm{I}_{\mathrm{m}}(\mathrm{hkl}) / \mathrm{I}_{0}(\mathrm{hkl}) /(1 / \mathrm{n})\left\{\mathrm{I}_{\mathrm{m}}(\mathrm{hkl}) / \mathrm{I}_{0}(\mathrm{hkl})\right\}$ for (111) and (220) reflection [65], as a function of substrate bias are shown in Fig 10. Where $I_{m}(h k l)$ is the observed intensity of the (hkl) plane, $\mathrm{I}_{0}(\mathrm{hkl})$ is the standard data (JCPDS) of the (hkl) plane, and $\mathrm{N}$ is the total number of diffraction peaks. When the TC value is larger than 1, a preferred orientation exists in the sample. The texture coefficient of the (111) orientation is significantly higher than that of the (220) orientation in the substrate bias range 0 to $-100 \mathrm{~V}$. When deposited lower film thickness it has been shown that the influence of surface prevails over strain energy and (100) orientation expected, but it is higher film thickness have (111) orientation expected with vice versa [66]. However we observed the contrary result compared to other researchers for nitride coatings with substrate bias. This may be due to the ion input energy or chan- 
neling effect is not the major role for the change of orientation between (111) and (220) plane. At $-300 \mathrm{~V}$, the trend of texture has completely changed from (111) to (220) and texture coefficient value shows extensively higher value than that of the (111) and it was maintained at the higher bias voltage of $-400 \mathrm{~V}$. It attributed to the mutual effects of both $\mathrm{Ti}$ and Si elements for preferred growth orientation of the Ti-Si-C-N nanocomposite coating at higher substrate bias voltage.

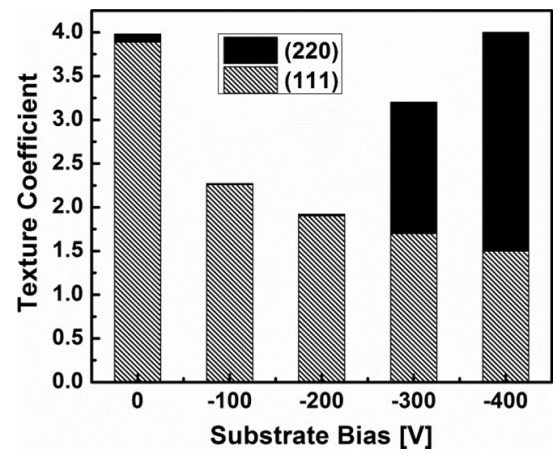

Figure 10. Texture Coefficient of the Ti-Si-C-N nanocomposite coatings various substrate bias voltage.

\subsubsection{Chemical Composition and Analysis}

To determine the composition of the Ti-Si-C-N nanocomposite coating, XPS analysis has been performed. The samples are sputtered with argon ions to remove the oxide top layer. Even though we found uniform oxygen concentration with respect to substrate bias voltage, could be due to the TMS gas which is used in the present studies. With increasing the negative bias voltage from 0 to $-300 \mathrm{~V}$, the silicon concentration increased from 5.17 to 8.14 at. \%. Silicon has lower electro negativity than carbon; amorphous carbon atom bonded to a silicon atom attracts electrons from the silicon atom, which condense the Si-H bonds. The number of silicon atoms attached to $\mathrm{Si}-\mathrm{Hx}$ is predicted to increase as silicon content increases in the Ti-Si-C-N nanocomposite coating [67]. In contrast, decreasing trend was observed for carbon content in the range from 40 to 24 at. \%. It may be due to carbon atom is lighter than the Si atom and also the energy of the Ar ion increases with cause to build strong bombarding to the substrate with increasing bias voltage. Further with increasing substrate bias voltage about $-400 \mathrm{~V}$, the silicon concentration shows decreasing trend in the range of 4 at.\%, it is also lower value than substrate bias voltage range of silicon content from 0 to $-300 \mathrm{~V}$. The $\mathrm{N}$ and Ti content are seen to be almost independent respect to the substrate bias.

The chemical state of the Ti-Si-C-N nanocomposite coating was analyzed by the XPS measurements and is as depicted in Fig. 11. Fig 11 (a) depicts the $C 1$ s peak spectra shows five component's namely, C1, C2, C3, C4 and C5 were observed in the spectrum zone. The two peaks of $\mathrm{C} 1$ (at $285.7 \mathrm{eV}$ ) and C2 (at $284.5 \mathrm{eV}$ ) corresponded with the position of $\mathrm{C}-\mathrm{N}$ and $\mathrm{C}=\mathrm{C}$ phase formation. Another three peak were peaks observed C3 (at $282.5 \mathrm{eV}$ ), C4 (at $281.2 \mathrm{eV}$ ) C5 (at 
$288.4 \mathrm{eV}$ ) corresponded with the position of Ti-C phase formation. As compared Ti-C peak position, the $\mathrm{C}=\mathrm{C}$ peak position accounts for only a small fraction of the total $\mathrm{C} 1$ spectra, indicating that a small fraction of $\mathrm{C}$ atoms are bonded to Ti atoms, and most of the $\mathrm{C}$ atoms exist as amorphous carbon [68,69]. Fig 11(b) depicts the Si $2 p$ peak spectra shows three components namely S1, S2 and S3 were observed in the spectrum zone. These two peaks of $\mathrm{S} 1$ (at $100.8 \mathrm{eV}$ ) and $\mathrm{S} 2$ (at $102.3 \mathrm{eV}$ ) corresponded with the position of $\mathrm{SiC}$ and $\mathrm{Si}_{3} \mathrm{~N}_{4}$ phase formation. Another one of weak component was observed at about S3 (at $102.8 \mathrm{eV}$ ) corresponds to Si-O bonds. The peak intensity gradually increased with an increase of bias voltage, which implies that increasing trend of silicon concentration. Fig. 11(c) depicts the N1s $2 p$ peak spectra shows three components namely N1, N2 and N3 were observed in the spectrum zone. These two peaks of N1 (at $398.28 \mathrm{eV}$ ) and N2 (at $396.64 \mathrm{eV}$ ) corresponded with the position of $\mathrm{Si}_{3} \mathrm{~N}_{4}$ and $\mathrm{TiN}$ phase formation. Another one of the weak component at about $\mathrm{N} 3$ (at $400.8 \mathrm{eV}$ ) corresponds to $\mathrm{C}-\mathrm{N}$ bonds. The formation of $\mathrm{Si}_{3} \mathrm{~N}_{4}$ phases was confirmed by XPS analyses for nanocomposite coatings. Figure 12 shows the HRTEM image of Ti-Si-C-N nanocomposite coatings deposited at a bias voltage of $-100 \mathrm{~V}$. These coatings are nanocomposite coatings of TiN nano-crystalline (black area) embedded in an amorphous matrix, which are clearly distinguished from the particles by high-resolution TEM image. The SAED patterns in the TEM analysis did not reveal any crystalline silicon nitride. Finally from the XRD, TEM and XPS result together confirmed that the Ti-Si-C-N coatings had nanocomposites structure of nanosized TiN crystallites embedded in an amorphous $\mathrm{Si}_{3} \mathrm{~N}_{4}$ matrix.
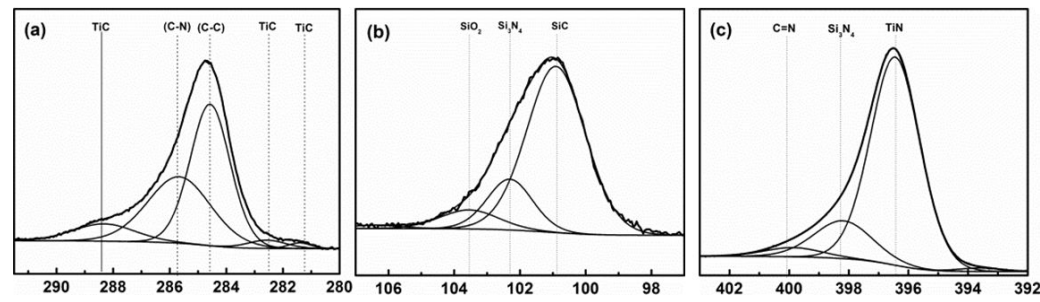

Figure 11. XPS spectra of Ti-Si-C-N nanocomposite coatings with various substrate bias voltage (a) C (b) Si and (c) N.

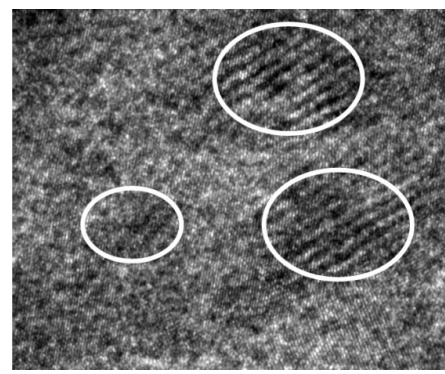

Figure 12. HRTEM image of Ti-Si-C-N coating at $-100 \mathrm{~V}$. 


\subsubsection{Nano Mechanical Properties}

Figure 13 shows the effect of substrate biasing on the hardness of Ti-Si-C-N nanocomposite coating. It was clearly seen that the hardness increases initially with the increase in the indentation depth upto $30 \mathrm{~nm}$. After that the hardness starts to decrease with increase in the penetration depth and finally attains saturation. This saturation in hardness value is observed in all the coatings. Hence this clearly indicates that at higher penetration depths, the obtained hardness may be due to the substrate effect. Hence, as per the Oliver-Pharr [70], the extracted hardness values are only from the $10 \%$ of the film thickness. Hence, for the un-biased Ti-Si-C-N coating, at the depth of about $30 \mathrm{~nm}$, the peak hardness was found to be $49 \mathrm{GPa}$. A maximum value of $49 \mathrm{GPa}$ has been obtained for the coatings deposited at a substrate bias of $-100 \mathrm{~V}$. This peak in hardness value is well corroborated with XRD, XPS and TEM studies. Furthermore increasing trend of hardness with bias voltage have been also studied many researchers by using different PVD synthesis methods. Usually enhancement of the packing density in plane of (111) were improved with increasing the substrate bias voltage and also from in our XRD pattern already confirms about orientation (111) has been formed at this bias range of coating. It is well known resultant microstructure of the film depends on the ion bombardment [71], and this in turn affects the hardness of the film. Also from the TEM analysis we have confirmed nanocrystalline phase formation with amorphous phase formation in this range of bias $(-100 \mathrm{~V})$ coating, it may be another reason for peaking hardness at this range of nanocomposite coating. Finally with increase the substrate bias the energy of the bombarding ions increases, causing structural modification, which is responsible for changes in the level of the hardness. However, a drastic drop of hardness observed from 49 to $20 \mathrm{GPa}$ over the range -100 and $-200 \mathrm{~V}$ was observed. The film hardness between -200 to $-300 \mathrm{~V}$ substrate biases remained constant at a value of about $18.5 \mathrm{GPa}$. We already pointed out in our XRD result shows the preferred orientation of (220) and stress formation with more defects this causes decreasing hardness. Therefore we can conclude that the hardness of nanocomposite coating depends directly on the substrate bias of nanocomposite coating in this present studies.

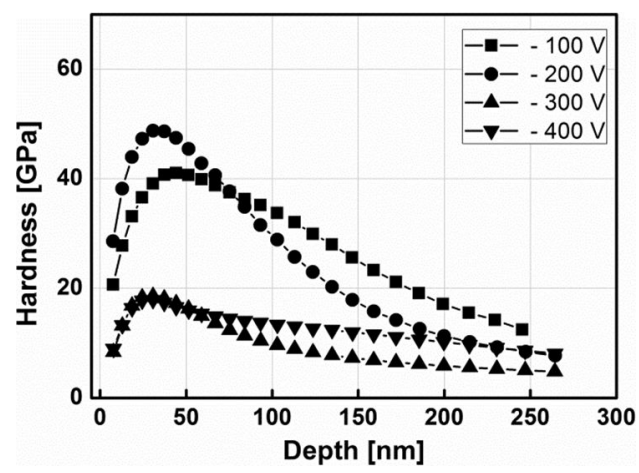

Figure 13. Nanohardness as a function of displacement into surface at various substrate voltages. 


\section{Summary}

Ti-Si-C-N nanocomposite thin films on stainless steel were prepared by using FVA technique at constant gas mixture of argon and nitrogen flow rate with room temperature. The nanocomposite films with silicon content in the range of 2.1 to 16.2 at. \% was prepared on stainless steel substrate with different TMS gas using FVA technique. From the XRD pattern, we have confirmed nancomposite structure like nc-TiCN/a- $\mathrm{Si}_{3} \mathrm{~N}_{4}$ formation. The nanocrystallite size of the samples decreases with the silicon content. Nanohardness measurement indicated a peak hardness of $\sim 49 \mathrm{GPa}$ and Young's modulus of $\sim 245 \mathrm{GPa}$ for the films with Si content of 3 at.\%. All these results show that Ti-Si-C-N nanocomposite coatings are suitable for surface coatings applications requiring low roughness, moderate hardness and low friction coefficient.

In the variation of substrate bias, we found (111) orientation at lower bias voltage range from 0 to $-100 \mathrm{~V}$, whereas the (220) orientation has confirmed at higher bias voltage range from -200 to $-400 \mathrm{~V}$. XPS result of Ti-Si-C-N coatings has confirmed the formation of nc$\mathrm{Ti}(\mathrm{C}) \mathrm{N} / \mathrm{a}-\mathrm{Si}_{3} \mathrm{~N}_{4}$ phase with respect bias voltage. The highest hardness around at $49 \mathrm{GPa}$ has achieved phase at the bias voltage of $-100 \mathrm{~V}$. Further increasing voltage the hardness was decreased due to stress and orientation behavior on this coating. By changing the bias voltage to change microstructure and chemical natural of the films and to improve tribological applications such as hardness and adhesion properties, it shows promising future in industrial fields.

\section{Author details}

Seunghun Lee, P. Vijai Bharathy, T. Elangovan, Do-Geun Kim and Jong-Kuk Kim

*Address all correspondence to: dogeunkim@kims.re.kr

Korea Institute of Materials Science, Changwon, Republic of Korea

\section{References}

[1] Yang, Sheng-Min, Chang, Yin-Yu, Wang, Da-Yung, Lin, Dong-Yih, \& Wu, WeiTe. (2007). Journal of Alloys and Compounds, 440, 375-379.

[2] Miller, H. C. (1981). J. Appl. Phys., 52, 4523.

[3] Aksenov, I. I., Strel'nitskij, V. E., \& Vasilyev, V. V. (2003). D.Yu. Zaleskij. Surf. and Coat. Technol., 163-164, 118-127.

[4] Sanders, D. M., \& Anders, A. (2000). Surf. Coat. Technol., 133/134, 78-90. 
[5] Aksenov, I. I., Vakula, S. I., Padalka, V. G., \& Khoroshikh, V. M. (1980). Sov. 350 mA when the arc current was $60 \mathrm{~A}$ and the extrac-. Phys. Tech. Phys., 25, 1164.

[6] Kim, Jong-Kuk, Lee, Kwang-Ryeol, Eun, Kwang Yong, \& Chung, Kie-Hyung. (2000). Surf. Coat. Technol., 124, 135-141.

[7] Chang, Yin-Yu, Wang, Da-Yung, \& Hung, Chi-Yung. (2005). Surf. Coat. Technol., 200, 1702-1708.

[8] Tanaka, Y., Ichimiya, N., Onishi, Y., \& Yamada, Y. (2001). Surf. Coat. Technol., 146-147, 215-221.

[9] Li, Chen., Yong, Du., Wang, Ai J., Wang, She. Q., \& Zhou, Shu. Z. (2009). Int. Journal of Refractory Metals \& Hard Materials, 27, 718-721.

[10] Bujak, J., Walkowicz, J., \& Kusinski, J. (2004). Surf. Coat. Technol., 180-181, 150-157.

[11] Ozturk, A., Ezirmik, K. V., Kazmanl, K., Urgen, M., Eryılmaz, O. L., \& Erdemir, A. (2008). Tribology International, 41, 49-59.

[12] Choi, Sung Ryong, Park, In-Wook, Kim, Sang Ho, \& Kim, KwangHo. (2004). Thin Solid Films, 447-448, 371-376.

[13] Kim, KwangHo, Choi, Sung-ryong, \& Yoon, Soon-young. (2002). Surf. Coat. Technol, 298, 243-248.

[14] Kim, Do-Geun, Svadkovski, Igor, Lee, Seunghun, Choi, Jong-Won, \& Kim, Jong-Kuk. (2009). Current Applied Physics, 9, S179-S181.

[15] Gorokhovsky, V. I., Bowman, C., Gannon, P. E., Van Vorous, D., Voevodin, A. A., Muratore, C., Kang, Y. S., \& Hu, J. J. (2008). Wear, 265, 741-755.

[16] Gorokhovsky, V., Bowman, C., Gannon, P., Van Vorous, D., Voevodin, A. A., Rutkowski, A., Muratore, C., Smith, R. J., Kayani, A., Gelles, D., Shutthanandan, V., \& Trusov, B. G. (2006). Surf. Coat. Technol., 201, 3732-3747.

[17] Chang, Chi-Lung, Chen, Jun-Han, Tsai, Pi-Chuen, Ho, Wei-Yu, \& Wang, Da-Yung. (2008). Surf. Coat. Technol., 203, 619-623.

[18] Park, In-Wook, \& Kim, KwangHo. (2002). Journal of Materials Processing Technology, 130-131, 254-259.

[19] Lee, Eung-Ahn, \& Kim, KwangHo. (2002). Thin Solid Films, 420-421, 371-376.

[20] Ma, S.L., Ma, D.Y., Guo, Y., Xu, B., Wu, G.Z., Xu, K.W., \& Chu, Paul K. (2007). ActaMaterialia, 55, 6350-6355.

[21] Guo, Yan, Ma, Shengli, Xuand, Kewei, \& Bell, Tom. (2008). Nanotechnology, 19, 215603.

[22] Kim, Soo Hyun, Kim, Jong Kuk, \& Kim, KwangHo. (2002). Thin Solid Films, 420-421, 360-365. 
[23] Rebouta, L., Tavares, C. J., Aimo, R., Wang, Z., Pischow, K., Alves, E., Rojas, T. C., \& Odriozola, J. A. (2000). Surf. Coat. Technol., 133-134, 234-239.

[24] Khizhnyak, N. A. (1965). Sov. Phys. Technol. Phys., 35, 847.

[25] Aksenov, I. I., Belous, V. A., \& Padalka, V. G. (1978). USSR Authors Certificate No. 605425, (Rus.).

[26] Aksenov, I. I., et al. (1978). Prib. Tekhn. Ehksp., 5, 236, (Rus.).

[27] Anders, A., Anders, S., \& Brown, I. G. (1995). Plasma Sources Sci. Technol., 4, 1-12.

[28] Martin, P. J., \& Bendavid, A. (2001). Thin Solid Films, 394, 1-15.

[29] Aksenov, I. I., Vasilyev, V. V., Druz, B., Luchaninov, A. A., Omarov, A. O., \& Strel'nitskij, V. E. (2007). Surf. Coat. Technol., 201, 6084-6089.

[30] Byon, E., Kim, J.-K., Kwon, S.-C., \& Anders, A. (2004). IEEE Trans. Plasma Sci., 23, 433-439.

[31] Aksenov, I. I., Zaleskij, D.Yu., \& Strel'nitskij, V. E. (2000). 1st International Congress on Radiation Physics, High Current Electronics and Modification of Materials, September, Tomsk, Russia. Proceedings 3, 130.

[32] Takikawa, Hirofumi, \& Tanoue, Hideto. (2007). IEEE Trans. Plasma Sci., 35(4), 992-999, Aug. 2007.

[33] Karpov, D. A. (1997). Surf. Coat. Technol., 96(1), 22-33, Nov. 1997.

[34] Martin, P. J., Bendavid, A., \& Takikawa, H. (1999). J. Vac. Sci. Technol. A, Vac. Surf. Films, 17(4), 2351-2359, Jul. 1999.

[35] Anders, A. (1999). Surf. Coat. Technol., 120/121, 319-330.

[36] Martin, P. J., \& Bendavid, A. (2001). Surf. Coat. Technol., 142-144, 7-10.

[37] Anders, A. (2002). Vacuum, 67(3/4), 673-686, Sep. 2002.

[38] Aksenov, I. I., Strel'nitskij, V. E., Vasilyev, V. V., \& Zaleslij, D. Y. (2003). Surf. Coat. Technol., 163/164, 118-127.

[39] Shi, X., Tay, B. K., Tan, H. S., Liu, E., Shi, J., Cheah, L. K., \& Jin, X. (1999). Thin Solid Films, 345(1), 1-6, May 1999.

[40] Tay, B. K., Zhao, Z. W., \& Chua, D. H. C. (2006). Mater. Sci. Eng. R, 52(1-3), 1-48, May 2006.

[41] Ryabchikov, A. I., \& Stepanov, I. B. (1998). Rev. Sci. Instrum., 69(2), 810-812, Feb. 1998.

[42] Zimmer, O. (2005). Surf. Coat. Technol., 200(1-4), 440-443, Oct. 2005.

[43] Chun, S. Y., Chayaraha, A., Kinomura, A., Tsubouchi, N., Heck, C., Horino, Y., \& Fukui, H. (1999). Jpn. J. Appl. Phys., 38(4B), L467-L469, Apr. 1999. 
[44] Meyer, C. F. H., \& Scheibe, J. (1999). Presented at the Int. Conf. Metallurgical Coatings Thin Films (ICMCTF), San Diego, CA, Paper B4-9.

[45] Taki, Y., Kitagawa, T., \& Takaki, O. (1997). J. Mater. Sci. Lett., 16(7), 553-556, Apr. 1997.

[46] Yoshitake, T., Shiraishi, G., \& Nagayama, K. (2002). Appl. Surf. Sci., 197/198, 379-383.

[47] Ning Jiang, Y. G., Shen, H. J., Zhang, S. N., \& Bao, X. Y. Hou. (2006). Materials Science and Engineering: B, 135, 1-9.

[48] Guo, Y., Shengli, M., \& Xu, K. (2007). Surf. Coat. Technol., 201, 5240-5243.

[49] Abraham, S., Choi, E. Y., Kang, N., \& Kim, K. H. (2007). Surf. Coat. Technol., 202, 915-919.

[50] Guo, Y., Ma, S. L., Xu, K. W., Bell, T., Li, X. Y., \& Dong, H. (2008). Key Engineering Materials, 373, 188-191.

[51] Qin, C. P., Zheng, Y. G., \& Wei, R. (2010). Surf. Coat. Technol., 204, 3530-3538.

[52] Shtansky, D. V., Levashov, E. A., Sheveiko, A. N., \& Moore, J. J. (1999). Metallurgical And Materials Transactions A, 30, 2439-2447, JCPDS File No: 42-1489.

[53] Diserens, M., Patscheider, J., \& Lévy, F. (1998). Surf. Coat. Technol., 108, 241-246.

[54] Phinichka, N., Chandra, R., \& Barber, Z. H. (2004). J. Vac. Sci. Technol. A., 22, 477-482.

[55] Johnson, L. J. S., Rogström, L., Johansson, M. P., Odén, M., \& Hultman, L. (2010). Thin Solid Films, 519, 1397-1403.

[56] Oliver, W.C., \& Pharr, G.M. (1992). J. Mater. Res., 7, 1564-1583.

[57] Dayan, M., Shengli, M., \& Xu, K. (2005). Surf. Coat. Technol., 200, 382-386.

[58] Jeon, J. H., Choi, S. R., Chung, W. S., \& Kim, K. H. (2004). Surf. Coat. Technol., 188-189, 415-419.

[59] Veprek, S., \& Reiprich, S. (1995). Thin Solid Films, 268, 64-71.

[60] Xu, H., Nie, X., \& Wei, R. (2006). Surf. Coat. Technol., 201, 4236-4241.

[61] Sundgren, J.-E., Johansson, B.-O., Hentzell, H. T. G., \& Karlsson, S.-E. (1983). Thin Solid Films, 105, 385.

[62] Zerkout, S., Achour, S., \& Tabet, N. (2007). J. Phys. D: Appl. Phys., 40, 7508.

[63] Pfeiler, M., Kutschej, K., Penoy, M., Michotte, C., \& Mitterer, Kathrein M. (2007). Surf. Coat. Technol., 202, 1050.

[64] Lee, D. N. (1989). Journal of Material Science, 24, 4375.

[65] Zhao, J. P., Wang, X., Chen, Z. Y., Yang, S. Q., Shi, T. S., \& Liu, X. H. (1997). J. Phys. D: Appl. Phys, 30, 5. 
[66] Zhang, X., Weber, W. H., Vassell, W. C., Potter, T. J., \& Tamor, M. A. (1998). J. Appl. Phys., 83, 2820.

[67] Jiang, N., Shen, Y. G., Zhang, H. J., Bao, S. N., \& Hou, X. Y. (2006). Materials Science and Engineering, B 135, 1.

[68] Fallon, P. J., Veerasamy, V. S., Davis, C. A., Robertson, J., Amaratunga, G. A., Milne, W. I., \& Koskinen, J. (1993). Phys. Rev. B, 48, 4777.

[69] Oliver, W. C., \& Pharr, G. M. (2004). Journal of Material Research, 19, 3.

[70] Chun, Sung-Yong. (2010). Journal of the Korean Physical Society, 56, 1134. 